TRABAJOS DE PREHISTORIA

55, n. $^{\circ} 1,1998$, pp. 63 a 80

\section{LA MONUMENTALIZACIÓN DEL PAISAJE: PERCEPCIÓN Y SENTIDO ORIGINAL EN EL MEGALITISMO DE LA SIERRA DE BARBANZA (GALICIA)}

\author{
MONUMENTALIZING LANDSCAPE: \\ FROM PRESENT PERCEPTIONS \\ TO THE ORIGINAL MEANINGS \\ OF GALICIAN MEGALITHISM \\ (NW IBERIAN PENINSULA)
}

FELIPE CRIADO BOADO $\left(^{*}\right)$
VICTORIA VILLOCH VÁZQUEZ $\left(^{*}\right)$

\section{RESUMEN}

El estudio del paisaje como construcción social implica considerar sus dimensiones económicas, territoriales y simbólicas. Sería importante reconstruir cómo fue percibido el espacio natural y social, para lo que se debería construir una Arqueología de la Percepción que tendría entre sus objetivos evaluar el efecto de los rasgos naturales y artificiales del paisaje sobre sus observadores pretéritos. Aquí se propone una estrategia de aproximación basada en el análisis sistemático de los rasgos visuales de los monumentos prehistóricos y en la caracterización de los efectos escénicos y panorámicas relacionadas con ellos. Un examen detallado del patrón de emplazamiento de los megalitos y de sus condiciones de visibilidad y visibilización, permite reconocer regularidades que evidencian una voluntad intencional de remarcar su presencia y provocar artificialmente efectos dramáticos.Así, proponemos aproximarnos a una fenomenología de la percepción prehistórica sin incurrir en soluciones subjetivas.

El estudio se basa en una revisión del megalitismo de la Sierra de Barbanza (NO de la Península Ibérica). Su ob-

(*) Grupo de Investigación en Arqueología del Paisaje (GIAr$\mathrm{Pa})$, Universidad de Santiago de Compostela. Laboratorio de Arqueología, Edificio "Monte da Condesa", Campus Sur, 15706 Santiago de Compostela (A Coruña). Correo electrónico pharpa@usc.es

El artículo fue remitido en su versión final el 23-III-98. jetivo final es contribuir al estudio de las estrategias monumentales de configuración de los paisajes culturales en el neolítico europeo, además de aproximarse a la diacronía y proceso de formación de esas tradiciones.

\begin{abstract}
The study of Landscape as social construction implies considering its economic and territorial dimensions, as much as its symbolic ones. A major topic in such kind of studies is to reconstruct the ways as natural and social space was perceived by past societies. We ought approach the project of building an Archaeology of Perception. One of the aims of such research programme would be to evaluate the effect of natural and artificial landscape features on past human observers. This paper will argue that a possible strategy for studying these dimensions of past landscapes could be based on the systematic analysis of visual features of the prehistoric monuments and in the characterization of the escenic effects and vistas related to them. $A$ detailed analysis of the pattern of location of megalithic monuments, of their visibility and visibilization conditio$n s$, allow us to recognize certain regularities what display an intentional will to remark on the existence of the monument and provoke dramatic artificial effects. In such way we could approach a phenomenology of prehistoric perception without falling in mere subjetive solutions.
\end{abstract}


This study is based in a systematic review of the megalithic monuments from Sierra de Barbanza (NW Iberia). Its final scope is proposing theoretical and methodological standpoints to approach these phenomena, but as well producing a case-study to reconstruct monumental strategies to shape cultural landscapes in Neolithic Europe and observe the diacrony (ie, continuities and changes) of these traditions.

Palabras clave: Arqueología del Paisaje. Arqueología de la percepción. Espacio social. Espacio simbólico. Territorialidad. Megalitismo. Túmulos. Arquitectura.

Keywords: Landscape Archaeology. Archaeology of perception. Social space. Symbolic space. Territoriality. Megalithism. Monumentality. Barrows. Architecture.

\section{INTRODUCCIÓN}

Este trabajo es una revisión del megalitismo de la Sierra de Barbanza, una zona bien conocida en la Arqueología gallega y que fue estudiada monográficamente a principios de la pasada década por uno de los autores (Criado et alii, 1986). El objetivo de aquel estudio era descubrir, mediante los datos ofrecidos por la investigación paleoambiental, la distribución de monumentos y su patrón de emplazamiento, las formas de construcción del espacio social en época megalítica.

Desde entonces se han acumulando nuevos datos, han surgido nuevas perspectivas interpretativas y se han aplicado planteamientos teóricos y procedimientos metodológicos más rigurosos y de mayor resolución, por lo que parece oportuno volver a la sierra de Barbanza (SB en adelante) para ver cómo cambian las viejas hipótesis a la luz de los avances recientes.

En concreto, esta revisión intenta profundizar en tres temas que antes ni siquiera se planteaban. El primero es el estudio de las formas de percepción del espacio en la Prehistoria. El segundo es ensayar una aproximación metodológica al estudio de la espacialidad arqueológica que podemos denominar deconstructiva. Y el tercero es la definición de la diacronía del paisaje monumental.

$\mathrm{Al}$ igual que existe una Geografía de la Percepción, en los últimos años han aparecido trabajos que abogan por una Arqueología de la Percepción. En ellos se pretende reconstruir cómo era percibido el medio y el espacio social por las sociedades pretéritas; intentan descubrir el impacto de los elementos naturales y artificiales del paisaje sobre los seres humanos prehistóricos que los observaban.

Esta línea de investigación es de gran importancia por cuanto la comprensión del paisaje social no está completa si no se considera la dimensión perceptiva, si no se toman en cuenta las apreciaciones y posiciones de los individuos que construyeron y utilizaron un determinado paisaje. $\mathrm{Al}$ estudio de las tres dimensiones fundamentales del paisaje (la ambiental o espacio físico, la social o espacio utilizado y la cultural o espacio pensado)(1) habría que añadir entonces la dimensión perceptiva.

Sin embargo el estudio de esta dimensión presenta grandes problemas. Puede, con facilidad, llegar a ser subjetivo o subjetivizante. La noción de que, situado ante un determinado espacio, podemos descubrir el impacto que ese medio produjo en cualquier observador a partir de nuestras propias reacciones, no sólo se debe perseguir por idealista, sino sobre todo por mantener la ilusión de que el patrón de subjetividad no cambia, sino que se mantiene invariable independientemente del contexto social e histórico que se considere (2).

Otro problema que se puede apuntar afecta a los pilares básicos de la Arqueología de la percepción. Para hablar de percepción hace falta que haya un individuo-que-percibe. Este, sin embargo, no es cualquier ser humano, sino un tipo determinado de sujeto, concebido y que se concibe como observador ante el mundo, que se subjetiviza ante una realidad objetiva externa a él. Y esto, que es una actitud muy moderna, que sabemos que es el producto de la experiencia artística implantada en nuestra cultura desde el Renacimiento, no es un apriori de cualquier cultura. No se puede sostener la existencia de ese tipo de ser percibiente en cualquier sociedad y, en todo caso, antes de pretender estudiar la percepción arqueológica, hay que mantener ciertas cautelas críticas en este sentido. Con ello no se pretende decir que los individuos de sociedades diferentes a la nuestra no perciban ni tengan sentimientos. Sino que éstos, la dimensión y carácter de los mismos y la actitud individual ante las percepciones, están determinados por los códigos sociales. Hay por lo tanto que elucidar quién percibía y cómo y qué percibía.

(1) Véase esta categorización en Criado, 1993 b.

(2) Esto nos lleva a un tema distinto: la estrategia del logocentrismo, de la metafísica tradicional moderna.

T. P., 55, n. ${ }^{\circ} 1,1998$ 
Así pues, lo que procede no es tanto estudiar la percepción en su dimensión directamente individual o subjetiva, terreno peligroso para la Arqueología por las razones anteriores y por la ausencia de suficientes datos empíricos; sino descubrir los sistemas sociales que guían, orientan y predeterminan la percepción. En la medida en que fuéramos capaces de superar el nivel de las percepciones subjetivas, que resulta inaccesible, y situarnos en el nivel material sobre el que aquellas se construyen, podríamos realmente aproximarnos a una Arqueología de la Percepción. Esta estrategia implica por lo tanto un desplazamiento de objetivo. Podemos decir que consiste en estudiar la percepción en su objetividad. Se trata no de estudiar la percepción a escala individual (lo que el sujeto prehistórico sentía), sino a escala social (cómo se dirigían y controlaban aquellas sensaciones, cómo se imponía un cierto tipo de percepción). Así podremos, tal vez, aproximarnos a una fenomenología de la percepción prehistórica sin incurrir en simples apreciaciones subjetivas ni en los problemas que, desde nuestro punto de vista, tienen las estrategias y productos arqueológicos que se autodenominan fenomenológicas/os.

Esta investigación se puede basar en la reconstrucción de los procedimientos y tecnologías a través de los cuales un determinado paisaje social expresaba su sentido y, para individuos que conocían su código visual y simbólico, lo preestablecía. Esto se puede hacer mediante un análisis sistemático de los rasgos visuales de los monumentos prehistóricos y de la caracterización de los efectos escénicos y de las panorámicas relacionadas con ellos. El estudio del patrón de emplazamiento de los monumentos, de sus condiciones de visibilidad, particularmente de las cuencas visuales que se relacionan con ellos, y de su visibilización, nos permitirán reconocer las regularidades que muestran la voluntad de y la estrategia intencional para hacer perceptible un monumento, remarcar su presencia y provocar efectos dramáticos artificiales en relación con él. Para ello podemos analizar las formas de crear impactos visuales, horizontes escenográficos, contrastes de formas, texturas y colores.

El método y proceso de análisis concreto que seguiremos (Criado, 1997: ap. 2.4 y 2.6, Santos et alii, 1997: ap. 1) se puede resumir como un modo de de-construir el espacio arqueológico (incluyendo sus elementos naturales y artificiales) para aislar el modelo formal sobre el que ese espacio se articula y, a partir de la descripción de ese modelo, interpretar el sentido original del paisaje arqueológico considerado. El estudio se planteó como una aproximación de tipo zoom, que intenta revisar todas las escalas que componen el espacio arqueológico para reconocer el modelo formal de cada una de ellas y determinar si son semejantes o disímiles.

Dejando a un lado las propuestas de carácter teórico-metodológico, este estudio pretende contribuir a la reconstrucción de las estrategias que, a través de la arquitectura monumental megalíti$\mathrm{ca}$, permitieron configurar un paisaje cultural durante el Neolítico. Completando aproximaciones previas en este sentido (Criado 1989a, b, 1993b; Criado y Vaquero, 1993; Filgueiras y Rodríguez, 1994; Vaquero, 1989, 1990, 1992; Villoch, 1995a, b, c), pretendemos ahora considerar el espesor diacrónico de los paisajes monumentales. Este estudio permitirá ver cómo se construye y en qué medida cambia un paisaje cultural de larga tradición entre, posiblemente, el V y II milenios a.C.

El estudio se basó en una revisión sistemática del emplazamiento de los monumentos tumulares de la SB que incluyó su inspección con diferentes condiciones de luz y vegetación, la búsqueda de nuevos datos y la localización mediante GPS con corrección diferencial de los túmulos.

\section{LAS FORMAS DEL ESPACIO (DATOS)}

\subsection{La posibilidad}

La zona de estudio se corresponde con una sierra litoral limitada por pendientes muy pronunciadas y dominada por terrenos en los que predominan las formas suaves y planas; es idónea para este tipo de estudio gracias a que su paisaje natural y tradicional se conserva bastante bien, a que el impacto de la repoblación forestal es, en los sectores que nos interesan, nulo y a que predominan condiciones de vegetación abierta.

Uno de los motivos para revisar la zona fue la necesidad de evaluar el Impacto Arqueológico de varios Parques Eólicos proyectados para ser enclavados en lo alto de la sierra, trabajo que fue desarrollado por nuestro Grupo de Investigación de Arqueología del Paisaje de la Universidad de Santiago (Villoch y Barreiro, 1997). Esto no sólo nos brindó la ocasión de volver a revisar la zona, sino

T. P., 55, n. ${ }^{\circ} 1,1998$ 
también de hacerlo con una perspectiva integral y geográfica más amplia.

\subsection{La geografía}

La SB está en el centro de la península del mismo nombre (Fig. 1), constituye la divisoria de aguas entre las rías de Muros y Arousa, y alcanza los $685 \mathrm{~m}$ de cota máxima; la altitud media de la sierra se sitúa en torno a los $550 \mathrm{~m}$. Mientras el conjunto de la península está densamente ocupado, aquella está casi despoblada.

Los escarpes laterales de la sierra, de gran pen-

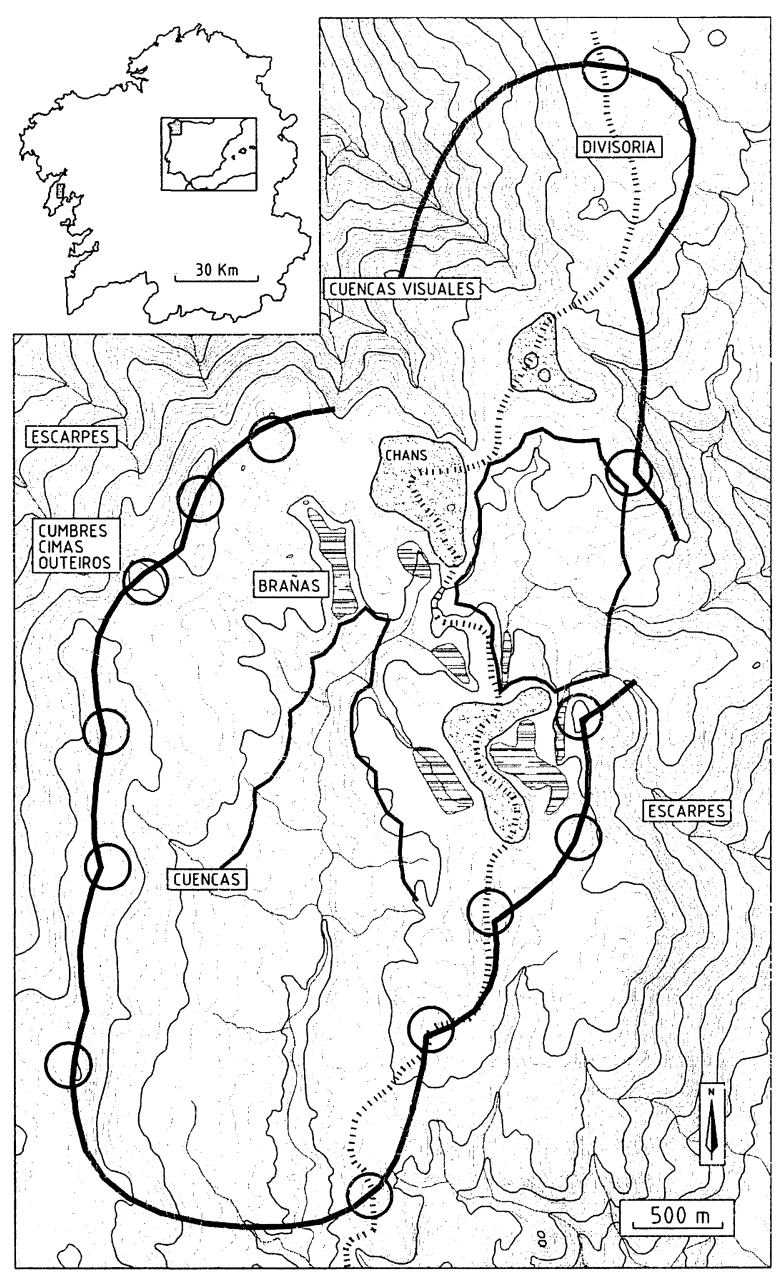

Fig. 1. Mapa de situación de la Península de Barbanza y de localización de la Sierra (en el recuadro). Análisis fisiográfico o morfológico de la Sierra: definición de las formas elementales del espacio físico. diente, se ven coronados por una superficie de erosión antigua en la que predominan las formas de relieve suave. Sobre ésta se ha incrustado el río Barbanza, que discurre en sentido N-S, entre una línea de cumbres al Oeste y una sucesión de planaltos al Este. Hacia el Sur, cuando el río inicia el descenso a través del escarpe lateral de la sierra, se encajona abruptamente formando un cañón o desfiladero que resulta casi infranqueable.

$\mathrm{El}$ análisis fisiográfico o morfológico (3) nos permite reconocer, a una escala de detalle, lo que hemos llamado formas elementales del espacio (Fig. 1). Este espacio presenta una divisoria longitudinal N-S constituida por la sucesión de tres formas llanas y suaves, que muestran una inflexión entre ellas y a las que se ha denominado tradicionalmente con el significativo nombre de chans (4) de Barbanza.

A ambos lados de ellas se encuentran dos valles (formas deprimidas), cabeceras de dos corrientes de agua: al Este la cuenca de A Graña, de formas amplias y suaves, y al Oeste la cuenca superior del río Barbanza, más larga y estrecha.

Las prolongaciones Norte y Sur de la divisoria dan lugar a una línea de cumbres accidentada, que se desdobla limitando la cuenca del Barbanza por su lado Oeste donde se encuentran las cimas más elevadas de la sierra (5), de modo que desde el interior de la SB la única forma de percibir grandes panorámicas visuales es desde las cimas laterales de la sierra y asomándose hacia el exterior de la misma. El espacio interior de la SB es cerrado visualmente (Lám. I).

El análisis del tránsito en la península (ver más abajo), nos muestra que la SB y, en concreto, su sector central se corresponde con un punto clave desde la perspectiva de la geografía de la movilidad. En puridad constituye un gran paso natural que permite organizar y distribuir los desplazamientos por la península (Fig. 3). El análisis de detalle de la SB nos permite identificar las diferentes líneas y claves de tránsito (Fig. 4).

El estudio del uso y ocupación del suelo ofrece unos contrastes muy relevantes, ya que mientras la

(3) Para evitar reiteraciones con análisis y descripciones que desarrollaremos con mayor profundidad, en vez de introducir una caracterización detallada del espacio estudiado siguiendo todos los pasos del proceso analítico al que nos ajustamos, nos limitaremos a comentar algunos rasgos generales en los que profundizaremos al hacer más adelante el análisis del espacio tumular.

(4) En gallego "llano".

(5) Alguno de los Parques Eólicos construidos en la sierra se disponen a lo largo de estas líneas de cumbres. 


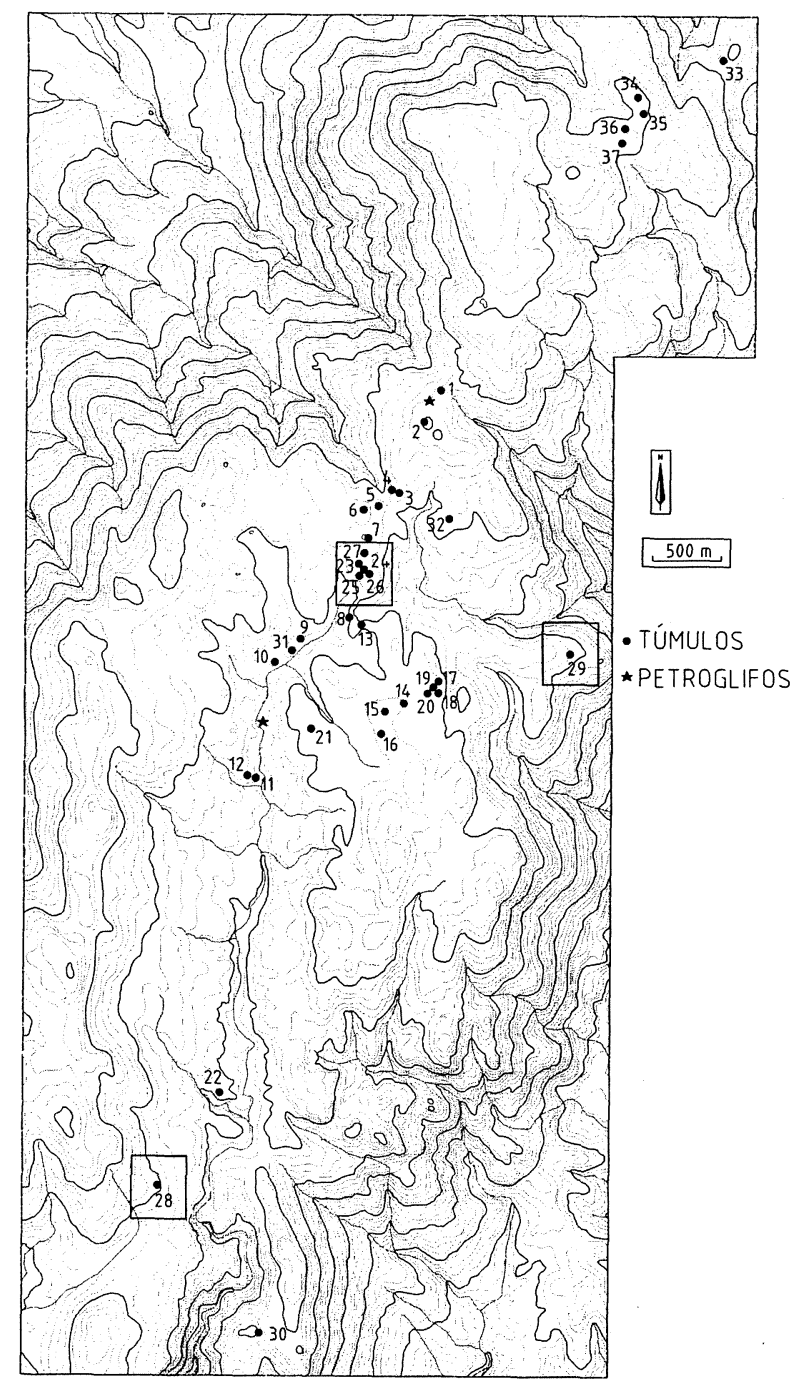

Fig. 2. Distribución de túmulos y petroglifos en la sierra.

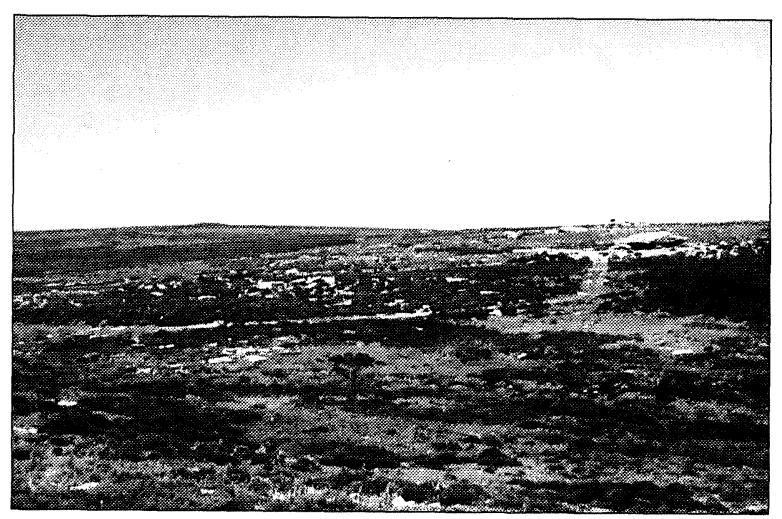

Lám. I. Vista panorámica del sector central de la Sierra de Barbanza.

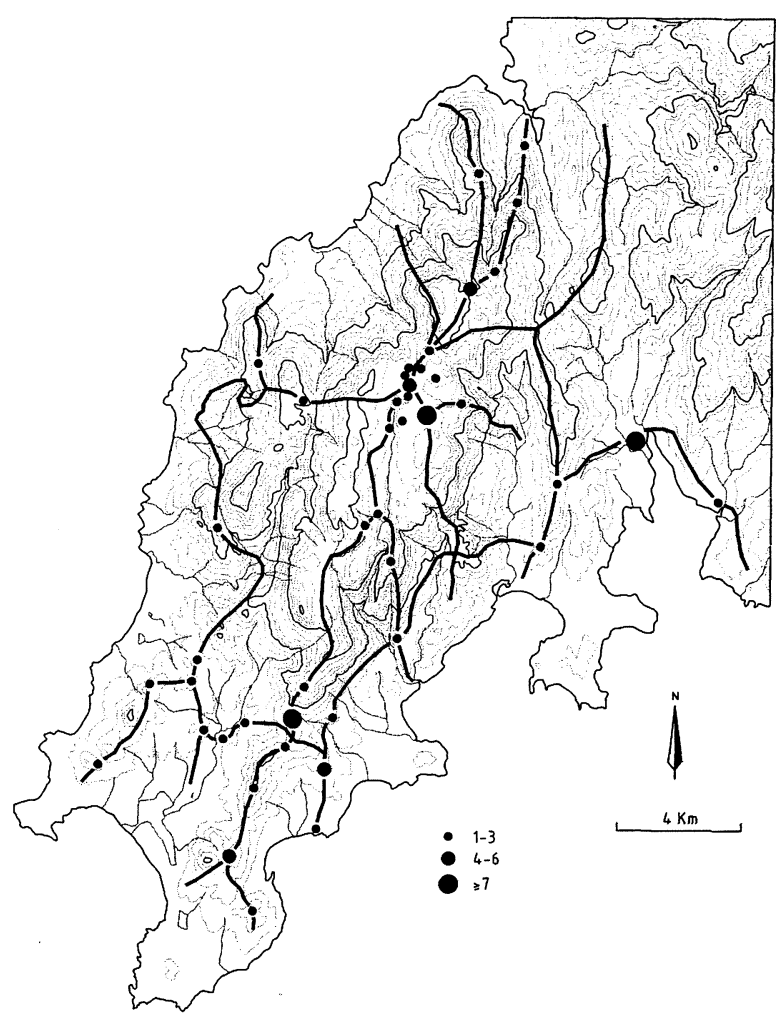

Fig. 3. Relación entre túmulos y geografía del tránsito en el conjunto de la Península de Barbanza.

mayor parte de la SB está ocupada por terrenos incultos y de monte, dedicado tradicionalmente a aprovechamientos extensivos, la cuenca deA Gra$\tilde{n} a$ constituye el único sector ocupado, aunque con escaso poblamiento ya que sólo existen 5 aldeas, y dedicado a agricultura de labradío. Sus características geográficas la convierten en el sector más idóneo de la SB para la agricultura intensiva y el asentamiento permanente: pequeña vaguada, reserva de agua y sin problemas de encharcamiento, bien orientada (a mediodía) y al tiempo resguardada de los vientos dominantes del SO (que traen las lluvias y nieblas marinas); todo ello motiva que las condiciones rigurosas que presenta la SB se dulcifiquen en este sector.

Todos estos análisis nos pérmiten definir lo que podemos llamar la red de lugares naturales estableciendo, además, la jerarquización de los mismos. El modelo resultante es un esquema topográfico ideal de la zona (Fig. 6) (6).

(6) El análisis topográfico considera afctores como vegetación, usos del suelo, o distribución del poblamiento, frente al fisiográfico o morfológico que se limita a tener en cuenta formas del relieve y del terreno. 

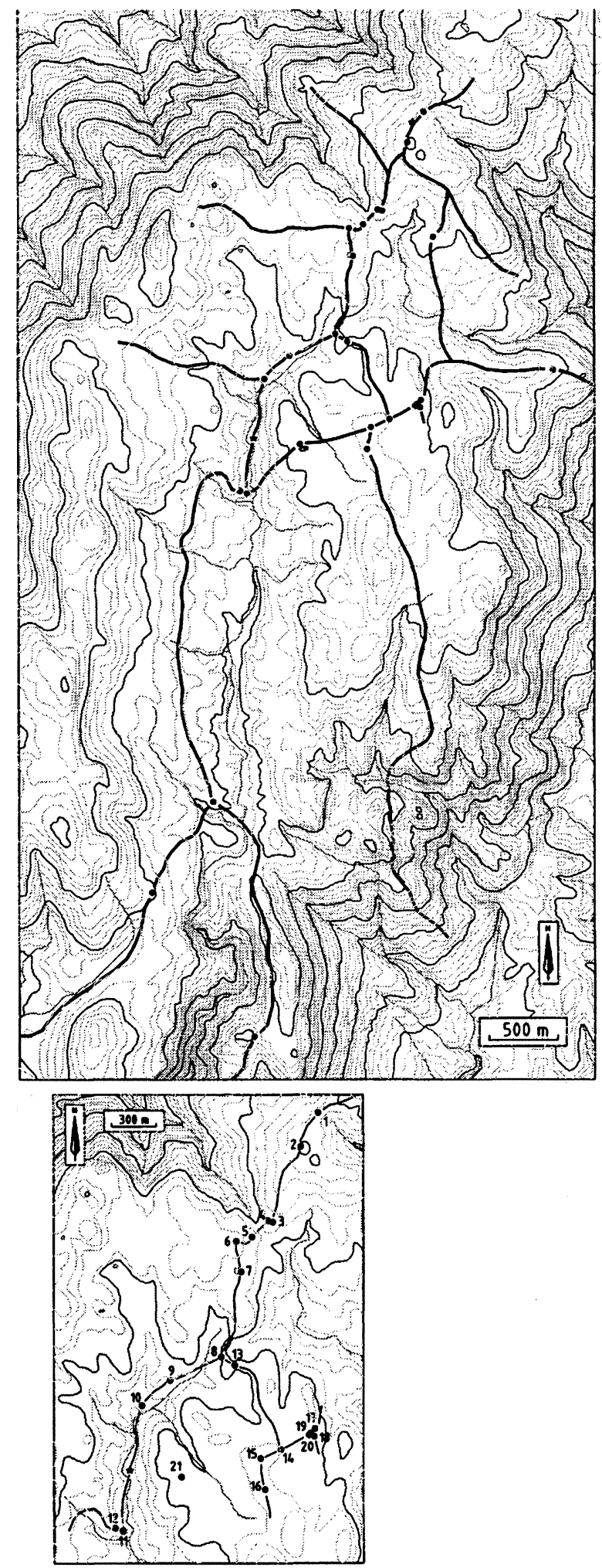

Fig. 4. Relación entre túmulos y geografía del tránsito en la sierra y, en el recuadro, en su sector central.

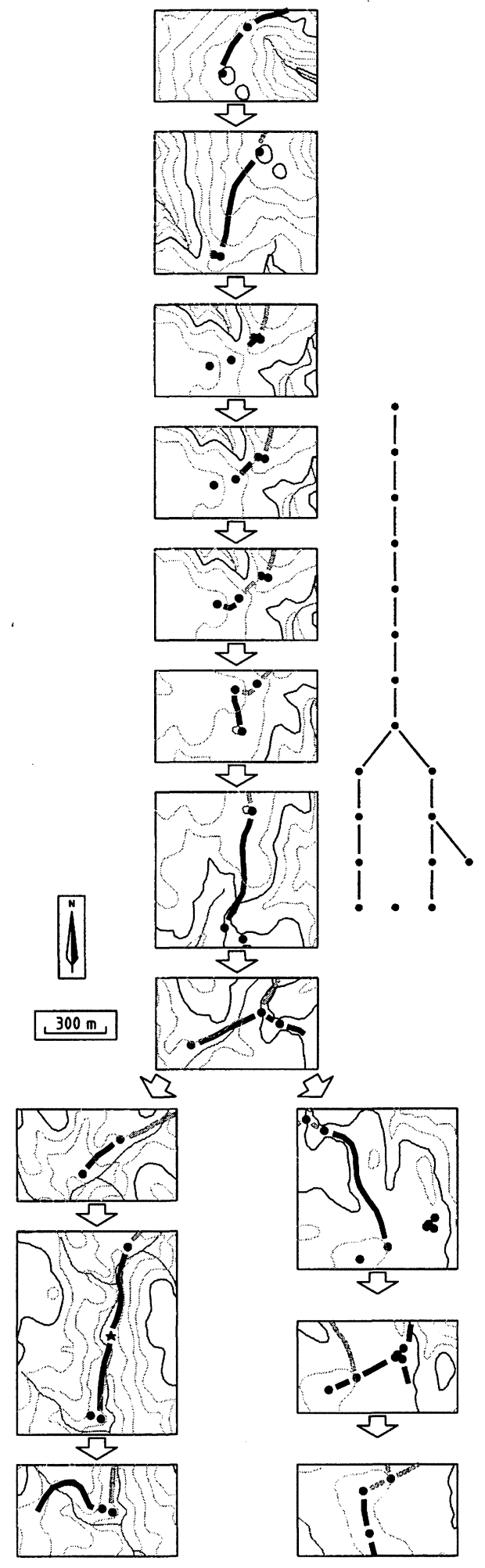

Fig. 5. Abstracción del patrón de desplazamiento representado por los túmulos y generación de un diagrama de permeabilidad del espacio tumular.

T. P., 55, n. ${ }^{\circ} 1,1998$ 

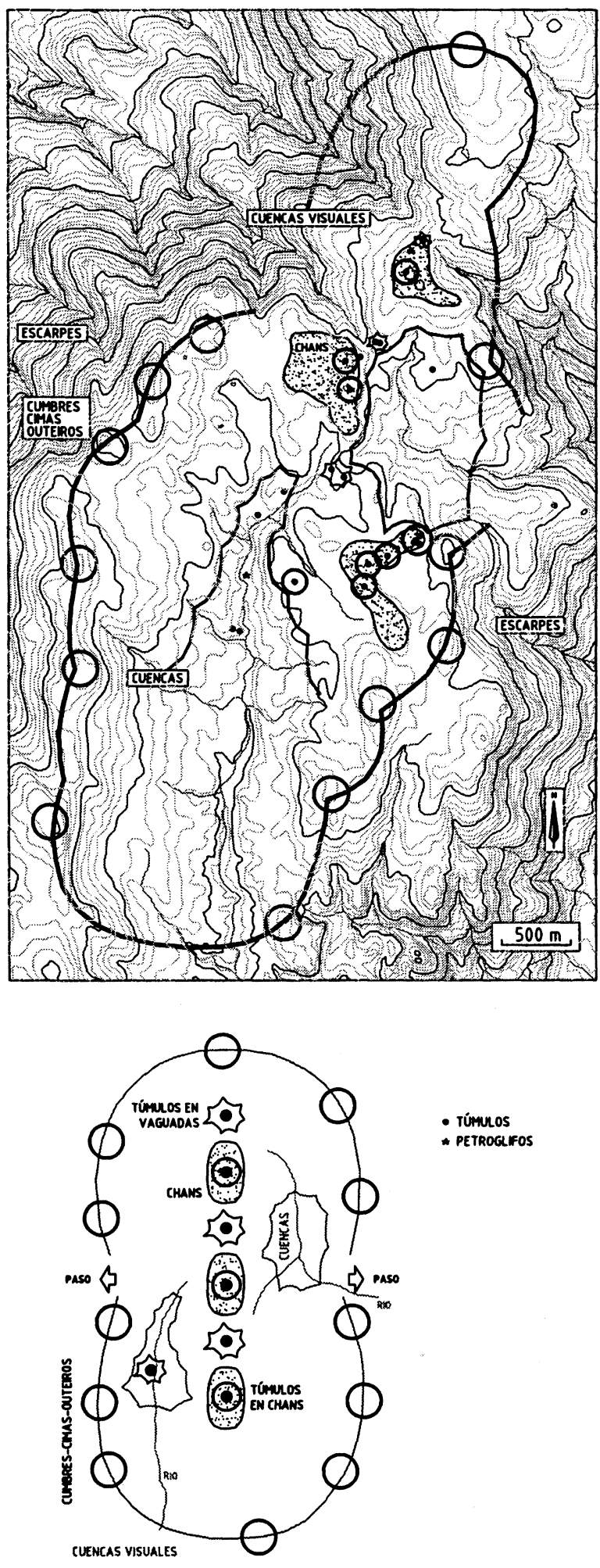

Fig. 6. Correspondencia entre túmulos y el esquema topográfico ideal de la sierra.

\subsection{El paleoambiente}

La sierra presenta en la actualidad importantes procesos de erosión, consecuencia de la desaparición de la cubierta vegetal en una zona con relieve de grandes pendientes y lluvias con alto índice de torrencialidad.

Sin embargo, a tenor de los análisis polínicos realizados y de la reconstrucción de la cubierta vegetal prehistórica, durante la época megalítica el medio estaba menos degradado que en la actualidad pero predominaban igualmente condiciones de vegetación abierta. En las zonas elevadas y chans se concentraba una pradera natural de gramíneas con árboles aislados; esto supone entre otras cosas un medio vegetal ideal para poder divisar los túmulos a media y larga distancia y, más en general, para constituir los juegos visuales que más abajo reconstruiremos.

En las zonas deprimidas que se corresponden con las cuencas de A Graña y del río Barbanza habría existido una vegetación más tupida y, al menos en las zonas más abrigadas, hidromorfas y con suelos profundos, habría extensiones de bosque de Quercus.

De la cuenca de A Graña proceden las únicas y limitadas evidencias sobre modificación humana del medio y, posiblemente, apertura de espacios de cultivo, tal y como muestra la aparición de polen de plantas ruderales debajo del paleosuelo del monumento de Casota do Páramo. Parece significativo que las escasas indicaciones de uso del suelo en momentos coetáneos a la construcción y uso de la necrópolis megalítica procedan de la misma zona en la que se ha concentrado el poblamiento y agricultura tradicional; esto se podría relacionar con la aptitud para el asentamiento de este sector de la sierra.

\subsection{El registro arqueológico}

En el conjunto de la península se conocen alrededor de 128 túmulos (Fig. 3). Aunque este inventario dista mucho de ser consecuencia de una inspección sistemática, su distribución presenta regularidades significativas.

La concentración más importante está precisamente sobre la SB, donde en una superficie de 3 $\mathrm{km}^{2}$ se encuentran 28 túmulos neolíticos (Fig. 2). En el resto de la sierra hay otros 10, dispersos y 


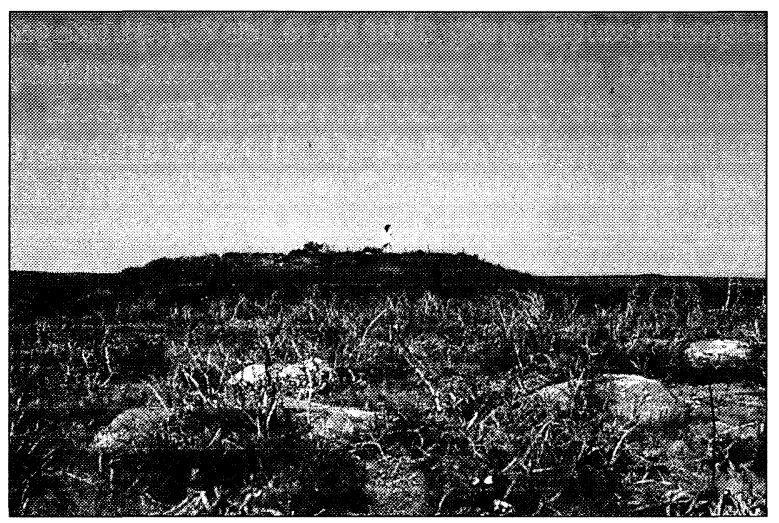

Lám. II. Ejemplo de emplazamiento de un monumento en la Sierra de Barbanza.

apartados unos de otros no menos de $4 \mathrm{~km}$ de distancia lineal (7).

Pertenecen a dos tipos bien definidos. El más frecuente se corresponde con túmulos circulares, de 20-25 m de diámetro y 2 m de altura (Lám. II) que encierran en su interior restos de cámaras megalíticas del tipo frecuente en Galicia: con losas de piedra granítica y corredor corto. Entre ellos figuran algunos de los ejemplares gallegos más monumentales: Casota do Páramo (3), Casarota do Fusiño (22) y Arca da Barbanza (11), que con sus $8 \mathrm{~m}$ de largo y corredor de dos tramos es una de las cámaras más grandes de Galicia. Además existen restos significativos de cámaras en otros cinco casos: $5,6,8,13,21$. De hecho, vamos a considerar inicialmente sólo este primer tipo de túmulos para, más adelante, volver sobre el segundo.

De este segundo hay 9 túmulos (números 23 , 24, 25, 26, 27, 28, 29 y dos más fuera de los límites de la Fig. 2) que presentan características totalmente distintas: pequeñas dimensiones, entre $10 \mathrm{y}$ $15 \mathrm{~m}$ de diámetro y $50 \mathrm{~cm}$ de altura, con cámara constituida por una cista pétrea. Mientras los primeros son prominentes y destacan con nitidez sobre el relieve circundante, los segundos son difíciles de diferenciar.

En el estado actual de nuestros conocimientos sobre las construcciones funerarias del megalitismo gallego, el segundo tipo parece corresponder al primer horizonte de la arquitectura monumental, que ha sido datado en cronología calibrada en torno al 4200-4000 BC. El otro tipo representa en

(7) Utilizaremos en este trabajo una numeración convencional; en la tabla 1 se indica la correspondencia entre ésta, la denominación tradicional de los monumentos y el número con que aparecen registrados en Criado et alii, 1996. cambio el grupo característico del momento pleno del megalitismo. Según dataciones calibradas fueron construidas entre el 4000 y el 3500 BC y habrían estado en uso hasta el $2800 \mathrm{BC}$ cal., momento en el que se cierran los corredores de acceso y parecen haber sido abandonadas (Alonso y Bello, 1997).

En los últimos años se han documentado en la sierra varias ejemplos de rocas con grabados de cazoletas, fenómeno asociado a los túmulos (Villoch, 1995b: 49-53). A pesar de que el conocimiento discontinuo de la distribución de estos grabados no nos permite su estudio sistemático, reconocemos en ellos la misma relación que en otras zonas gallegas (ver más abajo).

No conocemos otros elementos del registro arqueológico en SB. En principio podríamos sospechar la existencia de aldeas de la Edad del Bronce e, incluso, de algún tipo de asentamiento neolítico relacionado con los túmulos. El patrón de locali-

\begin{tabular}{|c|c|c|}
\hline $\mathbf{N}^{\circ}$ & DENOMINACIÓN TRADICIONAL & 1986 \\
\hline 1 & Outeiriño do Pan 2 & 2 \\
\hline 2 & Outeiriño do Pan 1 & 1 \\
\hline 3 & A Casota do Páramo & 3 \\
\hline 4 & Casota do Páramo 2 & 4 \\
\hline 5 & Armadoiro 2 & 6 \\
\hline 6 & Armadoiro 1 & 5 \\
\hline 7 & Pozas da Lagoa & 7 \\
\hline 8 & Cavada 2 & 14 \\
\hline 9 & Porto Traveso 3 & 15 \\
\hline 10 & Porto Traveso 1 & 17 \\
\hline 11 & Arca da Barbanza & 25 \\
\hline 12 & Arca da Barbanza 2 & 26 \\
\hline 13 & Cavada 1 & 13 \\
\hline 14 & Sabuceda 3 & 20 \\
\hline 15 & Sabuceda 2 & 19 \\
\hline 16 & Sabuceda 1 & 18 \\
\hline 17 & Sabuceda 6 & 23 \\
\hline 18 & Sabuceda 5 & 22 \\
\hline 19 & Sabuceda 4 & 21 \\
\hline 20 & Sabuceda 7 & - \\
\hline 21 & Outeiriño Redondo 2 & 4 \\
\hline 22 & Casarota do Fusiño 2 & 7 \\
\hline 23 & Pedra da Xesta 1 & 8 \\
\hline 24 & Pedra da Xesta 2 & 9 \\
\hline 25 & Pedra da Xesta 3 & 3 \\
\hline 26 & Pedra da Xesta 4 & 4 \\
\hline 27 & Pedra da Xesta 5 & 5 \\
\hline 28 & Monte Barbanza & 29 \\
\hline 29 & A Figueira & - \\
\hline 30 & Campo da Estivada & - \\
\hline 31 & Porto Traveso 2 & 16 \\
\hline 32 & Graña & - \\
\hline
\end{tabular}

Tab. 1. Numeración de túmulos, nombre tradicional y correspondencias con Criado et alii (1986). 
zación definido en Galicia para este tipo de asentamientos (Méndez, 1991, 1994; González, 1991) es coincidente con las condiciones geográficas: en concreto las cubetas ocupadas por brañas vinculadas a las formas planas del interior de la sierra y, sobre todo, a las cabeceras laterales de la cuenca de A Graña (ver más arriba).

A pesar de que no se ha realizado una prospección detenida orientada a la localización de este tipo de restos, lo cierto es que las condiciones existentes en la zona (monte bajo, vegetación abierta, frecuentes incendios forestales y apertura de pistas), podrían haber permitido identificar alguna evidencia de este tipo. De ahí que tal vez haya que considerar la falta de datos como prueba de ausencia.

\section{LA DECONSTRUCCIÓN DEL ESPACIO (ANÁLISIS)}

Los estudios realizados en Galicia han mostrado que los túmulos constituían el referente artificial de un paisaje cultural basado en la domesticación simbólica de la naturaleza. Esta domesticación se construía principalmente utilizando cuatro tipos de recursos cuya reiterada asociación al emplazamiento de los monumentos viene subrayada por relaciones visuales y de proximidad:

1. Asociación a las vías naturales de tránsito que hacen accesible un determinado espacio natural y permiten que, al transitar por ellas, se descubran los monumentos.

2. Asociación a rocas y accidentes naturales significativos que permiten realzar el efecto monumental y sirven para, conjuntamente con los monumentos, extender sobre el espacio circundante una red de hitos señeros y trasladar al conjunto del espacio una malla de referencias que lo haga cognoscible.

3. Asociación a otros monumentos anteriores, lo que permitiría construir la representación de una tradición social que se mantiene sobre un mismo territorio y lo articula.

4. Asociación a los asentamientos de sus constructores (8).

Ahora bien, al tiempo que en la SB se comprueba una vez más la recurrencia de estos facto-

(8) Mientras los puntos anteriores se observan de forma recurrente en los túmulos gallegos, esta última relación únicamente se ha comprobado en casos privilegiados del registro empírico. res, podemos ir más allá en el análisis y completar así nuestro conocimiento de las estrategias para construir un paisaje cultural a través de la arquitectura monumental.

\subsection{Monumentos $\mathbf{y}$ movimiento}

La asociación de los monumentos de la SB con el tránsito es tan estrecha que se podría pensar que el desplazamiento es el único y principal factor de emplazamiento tumular. Pero es sólo parte de un proceso complejo de localización que incluye fórmulas para hacer perceptibles los monumentos. Este fenómeno se puede observar en cuatro escalas de análisis sucesivas.

El estudio de la geografía de la movilidad a escala peninsular nos permite explicar la totalidad de la distribución de túmulos. Si se hace un mapa de vías y claves de tránsito (Fig. 3), se aprecia que: (1) todos los túmulos, formen conjuntos amplios o estén aislados, se vinculan a la red de tránsito (9), y (2) los conjuntos o necrópolis más importantes se asocian a los puntos claves del tránsito. Casi se puede decir que cuantas más líneas de tránsito confluyen en un punto, mayor número de túmulos hay en él.

Así, el factor que permite comprender la concentración de túmulos de la SB y que la mayor parte de ellos formen un núcleo abigarrado, es el hecho de que esa zona constituye un gran paso $\mathrm{na}$ tural, punto más adecuado para atravesar la barrera topográfica que representa la sierra. La forma más rápida y económica de realizar desplazamientos de larga distancia en la península consistía en subir la sierra a través de caminos laterales, acceder al espacio central en el que se sitúan los túmulos y tomar cualquiera de las rutas que allí confluyen para llegar al destino. Esta zona se convierte así en una especie de distribuidor de tráfico, en un cruce clave en el conjunto de la península (10).

Si descendemos un nivel más en la escala de observación se aprecia y completa la importancia

(9) Prueba indirecta es que cuando se abrió la Vía Rápida por la margen Sur, fue necesario hacer excavaciones de rescate en 4 túmulos (Dorna-Rianxo, A Barreira-Pobra do Caramiñal y VentínRibeira), pues el trazado de nueva planta aprovechaba puntos clave del terreno donde existían monumentos.

(10) La zona ha perdido esta funcionalidad debido a la creación de una red de comunicaciones moderna que se ha independizado del constreñimiento del relieve. En cambio, utilizando una analogía débil, podemos ver todavía esta función en el hecho de que todas las redes eléctricas que atraviesan la SB se cruzan prẹcisamente en este punto. 
de este factor ya que la distribución concreta de los monumentos del centro de la sierra está en función de las líneas de tránsito específicas que la atraviesan. Las rutas más importantes, aquellas que disponen de los mejores condicionantes físicos para el desplazamiento se identifican merced a la presencia y distribución de los túmulos particulares (Fig. 4).

Pero todavía podemos concretar mejor la relación si reducimos la escala de observación y realizamos un análisis de detalle. Cuando un viandante recorre las rutas naturales comprende que el modo de elegir la más adecuada es guiarse por los túmulos que percibe en la distancia; pero además, cuando llega a cruces y puntos de trayectoria ambigua, es la disposición puntual de los túmulos la que muestra la ruta a tomar. Esto es claro en puntos conflictivos en los que la percepción de un monumento en el horizonte ofrece una indicación equívoca, ya que en vez de seguir la línea que marca el monumento distante hay que hacer un giro en la ruta; en estos casos un segundo monumento, anejo al anterior, marca la dirección correcta a seguir (Fig. 4). Ejemplos concretos de esta localización lo ofrecen el túmulo 4 en relación con el 3, el 13 o el 12. En todos estos casos el monumento que se ve a lo lejos indica la orientación general, pero es la situación en escorzo del monumento próximo la que marca el giro que debe hacer el viandante.

Vemos pues que el tránsito permite entender no ya la distribución y emplazamiento de los túmulos de la sierra, sino también la configuración concreta de los grupos de túmulos y la posición local de éstos. Llegados a este punto sería fácil concluir que el movimiento es lo que explica todo y que la racionalidad de este modelo de emplazamiento se agota en una dimensión práctico-utilitaria según la cual los monumentos tendrían la función de mostrar el camino y serían la expresión formal de una especie de código de circulación (11). Los túmulos denotan una relación con los patrones de desplazamiento que permitía que cualquiera que conociera los principios de esta codificación pudiera transitar por este espacio, aunque lo desconociera. Sin embargo, es necesario mitigar el excesivo pan-transitismo que en los últimos años

(11) Sería también muy fácil correlacionar este hecho con la presunta vigencia durante el neolítico atlántico de patrones de asentamiento móviles, formas de uso del suelo protoagrícolas y una domesticación incipiente del medio que mantenía sobre todo un ambiente silvestre. sacude a algunas aplicaciones de la Arqueología del Paisaje que se resuelven en señalar la relación de los elementos arqueológicos con el movimiento.

Esta vinculación es más compleja; es el instrumento inicial de una tecnología para articular y organizar el paisaje cultural. La relación sirve para convertir la totalidad del espacio físico en un espacio construido, pues el tránsito crea vínculos entre los hitos artificiales que modifican ese espacio y le imponen un eje de referencias arquitectónicas.

Para ampliar nuestra investigación, nos serviremos de una aplicación heterodoxa de los diagramas de permeabilidad. Esta técnica, muy útil en el estudio de espacios construidos (Hillier y Hanson, 1984), nos permite crear un modelo abstracto de los patrones de acceso a un determinado espacio diferenciando sus estancias y los corredores, umbrales'o intervalos que hay entre ellos. En nuestro caso tomaremos cada túmulo como una estancia y cada etapa entre ellos como un corredor (Fig. 5). El esquema que obtenemos destaca por la simetría que contiene. Sin embargo, antes de profundizar en este punto, es preciso completar los restantes pasos del proceso analítico que seguimos (Santos et alii, 1997: ap. 1) y observar las correspondencias entre la distribución de túmulos y el análisis formal del espacio físico.

\subsection{Los monumentos en la naturaleza}

Se podría decir que en la SB la relación con accidentes naturales no parece haber sido especialmente importante; así, por ejemplo, la vinculación de los túmulos a afloramientos rocosos conspicuos no es mayoritaria; sin embargo, en la SB la relación con hitos naturales significativos adopta una morfología especial.

Una variante específica de esta relación sería la vinculación de túmulos con petroglifos con representaciones de cazoletas. Según estudios recientes (Villoch, 1995a, b) esta relación es recurrente y las cazoletas tienden a definir el arco de visibilidad inmediata del túmulo. Se sitúan en la zona de ruptura de pendiente, manteniendo la continuidad visual completa entre ellas y los túmulos y marcando en cambio una discontinuidad con lo que viene después. De este modo las cazoletas ocupan un borde topográfico que se convierte también en un límite visual y efectivo.

T. P., 55, n. ${ }^{\circ} 1,1998$ 
De este modo, las cazoletas habrían sido una señal artificial que identificaban la proximidad de un monumento, marcaban la línea de acceso hacia él situándose en el borde de la línea de tránsito y, posiblemente, limitaban el espacio sacral en torno al túmulo (Fig. 2). La cazoleta localizada entre los túmulos 1 y 2 habría tenido esta función. La cazoleta situada entre los monumentos 10 y 11 ofrece un ejemplo muy peculiar, se sitúa en el centro exacto del trayecto (12) sobre una roca de formas redondas y abultadas que marca el punto en el que la ruta entre ambos túmulos, siguiendo el río, debe pasar de la margen occidental a la oriental porque el relieve se hace demasiado escarpado e irregular por el poniente. En general, por lo tanto, las cazoletas sirvieron como un recurso técnico que artificializa y monumentaliza los elementos del espacio natural.

Pero la vinculación más importante con hitos naturales adopta una morfología distinta: los lugares significativos del espacio físico. Las referencias naturales concretas (rocas) se sustituyen por la situación de los túmulos en posiciones monumentalizadoras: outeiros y chans.

Esta observación puede parecer un tanto subjetiva o en todo caso inverificable. Necesita método y sistema. Cuando se compara la distribución de túmulos con el análisis de las formas elementales del espacio físico y, en definitiva, con su esquema topográfico, se observa que la totalidad (con excepción del 29) se emplazan sobre las principales formas topográficas (Fig. 6). Podemos ahora apreciar que la distribución de túmulos forma siete núcleos: tres de ellos se sitúan sobre cada uno de los chans antes definidos; otros tres en los puntos de inflexión entre ellos; y el séptimo en el interior de una de las dos cuencas individualizadas, la del Barbanza.

Es más, si retomamos el diagrama de permeabilidad y sobre él inscribimos la formas del relieve en las que se sitúa cada grupo, apreciamos que toma mayor vigor la apariencia inicial de simetría. A lo largo de los corredores del diagrama, se sucede una alternancia bajo//alto que, después de la bifurcación de la ruta en la mitad Sur, se concreta en que uno de los corredores se incrusta en un relieve bajo mientras el otro se extiende por una forma elevada (Fig. 5).

(12) La estimación se hizo utilizando tecnología de posicionamiento por satélite con corrección diferencial, lo que da a los coordenadas una precisión de 5 m (Amado, 1997).

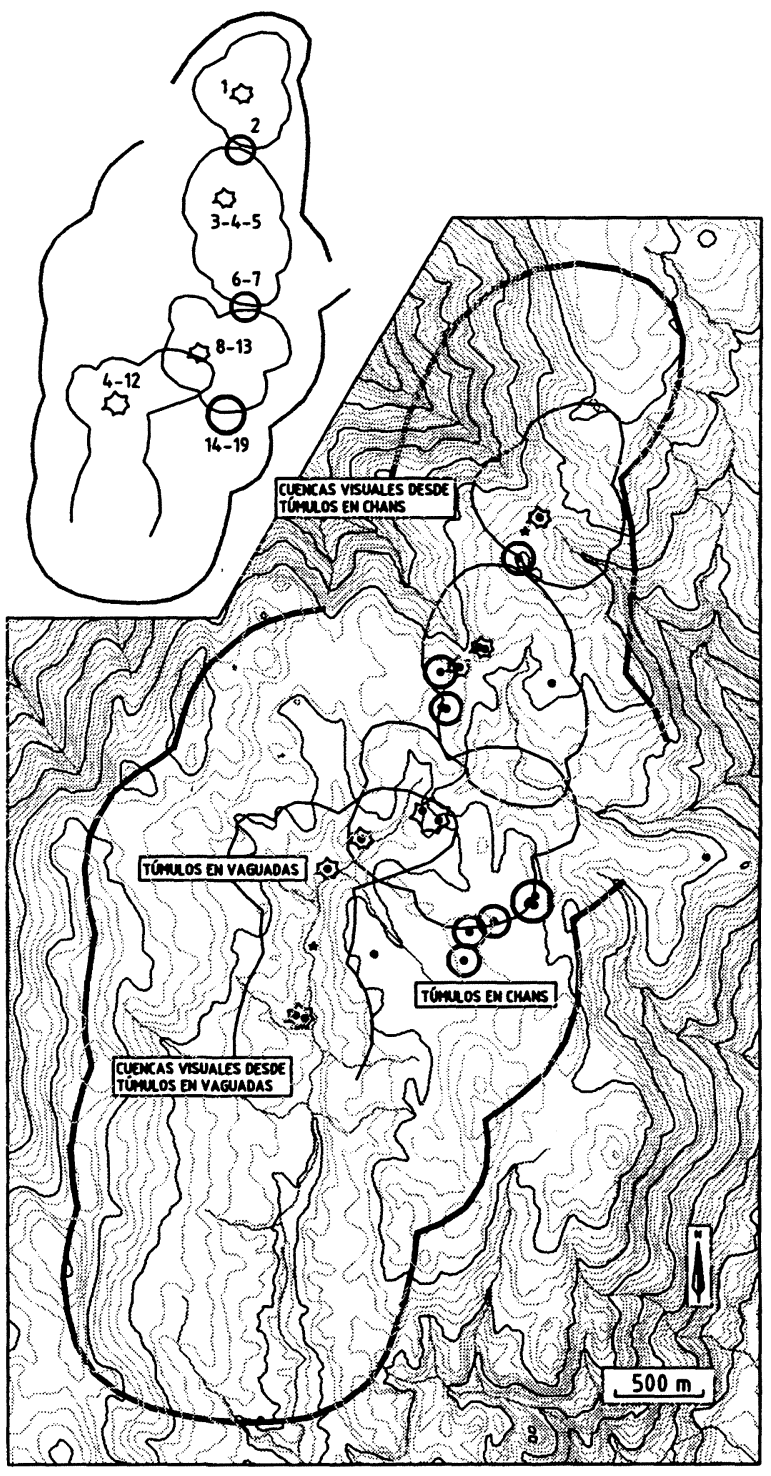

Fig. 7. Análisis de cuencas visuales y esquema de las panorámicas dominadas desde los túmulos de la sierra.

\subsection{Monumentos y cuencas visuales}

Los túmulos que estamos estudiando están situados de tal modo que alguno de ellos es visible incluso desde más de $2 \mathrm{~km}$ de distancia; lógicamente son aquellos situados sobre formas elevadas, y que además tienen mayor número de intervisibilidades con otros túmulos.

El análisis de las intervisibilidades nos muestra que, salvo algunas excepciones (en concreto 7: 1, $13,10,9,21,11$ y 12 , desde los que se distinguen 
menos de 4 túmulos), desde todos ellos se perciben un elevado número de monumentos: la media se sitúa en torno a 8-9 intervisibilidades y en algunos casos se superan las 15 (2, 6, 7, 14, 15 y 16) (13). Existe casi siempre intervisibilidad entre un túmulo y el inmediato (salvo en dos casos: entre 2 y 3 , y entre 7 y 8). Esto quiere decir que las etapas de la ruta se marcan mediante una relación visual.

Por otra parte, el análisis de las cuencas visuales percibidas desde los túmulos presenta una dualidad muy clara (Fig. 7). Los monumentos situados en posiciones deprimidas (inflexiones entre los chans o el valle del Barbanza) dominan una cuenca visual reducida. Mientras que los monumentos en posiciones elevadas controlan una cuenca visual más amplia.

Vemos entonces que la conjunción de rutas y visibilización monumental permiten atravesar el espacio y comprenderlo como un conjunto unitario. Basándose en el reconocimiento de los monumentos y de la red de movimiento relacionada con ellos se representa un modo de organización del espacio que contiene al mismo tiempo un mapa cognitivo y una forma de domesticación mental del ambiente. El discurso y la visión, el discurrir y el ver, producen una experiencia concreta del espacio físico, que de hecho transforma a éste en espacio social cargado de significados simbólicos. Dado que ese modo de organización se impone al observador cuando éste atraviesa el terreno, la percepción de ese modelo de paisaje constituye una experiencia vívida. A lo largo del camino, el observador recibe unas percepciones que tienen la virtualidad de representarle el sentido de ese paisaje social.

¿Podemos entonces aprender alguna otra cosa sobre ese paisaje analizando esas percepciones? Como decíamos antes no podemos acceder a su dimensión estrictamente subjetiva o individual, ni reconstruir de forma exacta cómo percibían el paisaje los individuos prehistóricos. Pero al menos podemos reproducir de forma aproximada los escenarios que daban pie a esas percepciones, ya que esa experiencia concreta del espacio físico construida por el discurso y la visión, produce una serie de cuencas visuales que se suceden para el observador a lo largo del espacio que atraviesa.

(13) Estos datos se obtuvieron cubriendo en el campo una matriz de visibilidades; son por lo tanto intervisibilidades reales y no aproximaciones derivadas de la cartografía o del uso de tecnología GIS.
A pesar de la dualidad que diferencia cuencas amplias y cuencas reducidas, la mayor parte de esos escenarios megalíticos poseen una forma básica semejante, caracterizada por la concurrencia de tres rasgos:

1. Comprenden una panorámica circular cerrada visualmente, delimitada por divisorias topográficas y que comprende un área deprimida o cubeta, tanto topográfica como visual; esto es especialmente claro y lógico en los túmulos situados en vaguadas, pero también ocurre con los emplazados sobre cerros; en este caso son las lejanas líneas de cumbres las que cierran el abanico visual.

2. El borde de esta panorámica está jalonado por accidentes naturales y por monumentos artificiales: sobre el límite principal (14) del horizonte visual se distingue siempre algún túmulo, a veces recortándose sobre la línea de horizonte.

3. 'El escenario suele tener un centro u ombligo bien individualizado desde el que se percibe su totalidad y que se identifica mediante la presencia de un túmulo, situado en la cima de la forma elevada o en el eje de la forma deprimida.

El modelo de escenario es siempre el mismo: círculos cerrados, con un centro monumental y un límite natural monumentalizado. Si inscribimos el esquema de cuencas visuales sobre el diagrama de permeabilidad (Fig. 8), percibimos que el tránsito produce una sucesión de dos escenas distintas que se ajustan a ese modelo básico y que se alternan: de acuerdo con las condiciones del relieve, en posiciones bajas se genera una panorámica reducida (escena 1), mientras en posiciones elevadas se obtiene una panorámica amplia (escena 2), pero en ambos casos el modelo del espacio percibido es el mismo. Estos rasgos también se observan en las cuencas visuales principales que se contemplan cuando se atraviesa el sector central de la SB aunque no se esté al lado de un túmulo o no se siga exactamente la red de tránsito antes definida. De este modo, el emplazamiento de los túmulos se convierte en el dispositivo artificial mediante el cual las diferencias y discontinuidades del espacio natural se domestican y convierten en espacios que se perciben como semejantes.

Creemos que el hecho de que se mantenga una forma regular en todos estos casos marca hasta

(14) Llamamos 'límite principal' a la primera línea de horizonte que se recorta en las visibilidades inmediatas y al que aparece a medio distancia pero siempre bien individualizado.

T. P., 55, n. $^{\circ} 1,1998$ 


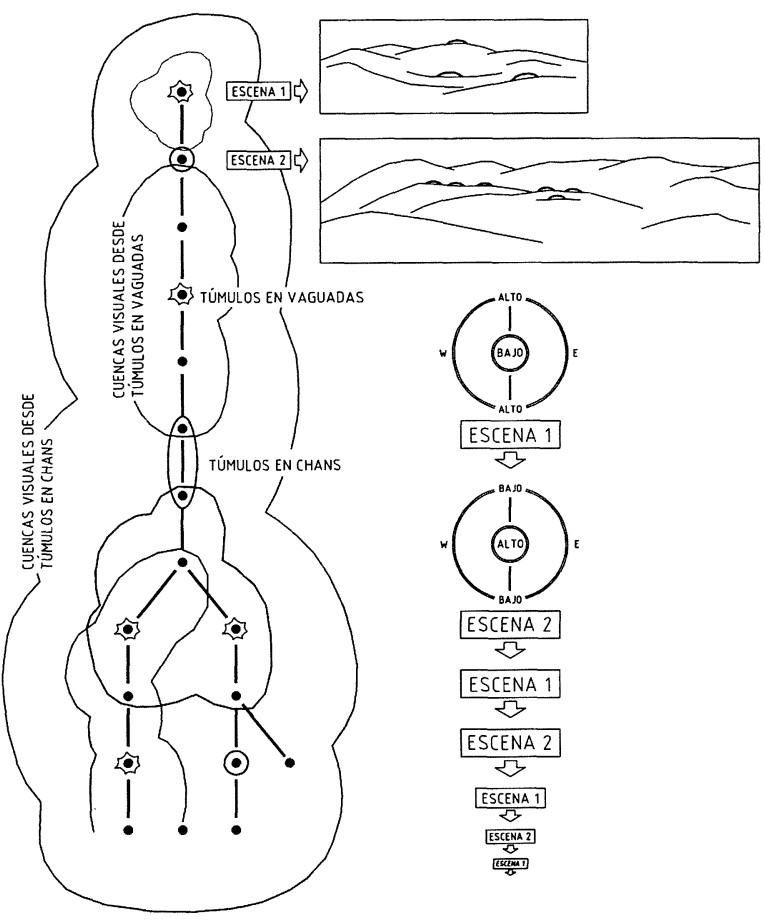

Fig. 8. Representación del esquema de panorámicas visuales sobre el diagrama de permeabilidad del espacio tumular: sucesión de escenas y modelo general de cada escena.

qué punto la percepción estaba guiada por la construcción de escenarios preestablecidos. La conservación de una forma regular en ambas situaciones es de gran importancia, ya que muestra la existencia de un sistema uniforme de articulación del territorio basado en la sucesión o yuxtaposición de escenarios circulares que, además, repiten el mismo modelo perceptivo.

\section{LA ORGANIZACIÓN DEL ESPACIO (RESULTADOS Y PERSPECTIVAS)}

\subsection{La estructura organizativa del paisaje monumental}

A partir del análisis formal del espacio físico y arqueológico, podemos ver que la experiencia del espacio construida por el paisaje megalítico se concreta en una sucesión de escenarios circulares presididos y delimitados por construcciones monumentales y articulados por la red de flujos del movimiento.
Sin embargo todavía podemos ir más allá en el análisis. Pues en vez de limitarnos a ver el espacio tumular de la SB como una sucesión de siete espacios o escenarios distintos, podemos intentar comprehenderlo como una unidad dentro de la cual se abrirían sectores específicos. La cuestión por lo tanto es: la organización del espacio tumular total de la SB ise limita a crear un orden mediante la agrupación de unidades discretas que repiten un mismo modelo $n$ veces, o reproduce él mismo un principio de orden que confiere identidad a la totalidad? En este caso hay que ver cuál sería el modelo formal que sigue el sistema general.

Nos anima a plantear esta última hipótesis el hecho de que la organización del sistema formal considerado presenta unas relaciones de simetría y proporción que sugieren la posibilidad de que funcionen en él principios organizadores de mayor escala que el nivel de cada grupo local de túmulos. Si observamos la sucesión de escenarios megalíticos sobre el diagrama de permeabilidad (Fig. 8) y le sobreimponemos el esquema fisiográfico, se aprecia que cada túmulo se encuentra en posición exactamente simétrica en el diagrama respecto al túmulo inverso. Es decir, dado un túmulo concreto del diagrama, el correspondiente inverso presentará características de emplazamiento paralelas a las de su complementario (Fig. 8).

Así encontramos que los túmulos 2 y 16 se encuentran en la misma posición relativa en el diagrama. Lo mismo ocurre con 4, 13 y 9, que marcan la transición entre las cuatro formas naturales ocupadas por los cuatro grupos de túmulos (los tres chans y el valle del Barbanza). El centro de la unidad central está marcado por dos túmulos simultáneamente: 6 y 7. Éstos representan el centro del sistema total, pues hacia el Norte y hacia el Sur existe el mismo número de intervalos o túmulos.

Estas observaciones se completan si, además del emplazamiento fisiográfico y relativo, consideramos otros factores como las relaciones de visibilidad: los túmulos que marcan el centro de cada unidad son los más visibles del sistema (ie: los que se ven desde cualquiera de las unidades e incluso desde su exterior) y poseen además el mayor número de intervisibilidades.

Finalmente, el juego de correspondencias simétricas en el espacio tumular de la SB se completa al considerar lo que en principio podría parecer el caso aberrante de unidad tumular que se corres- 


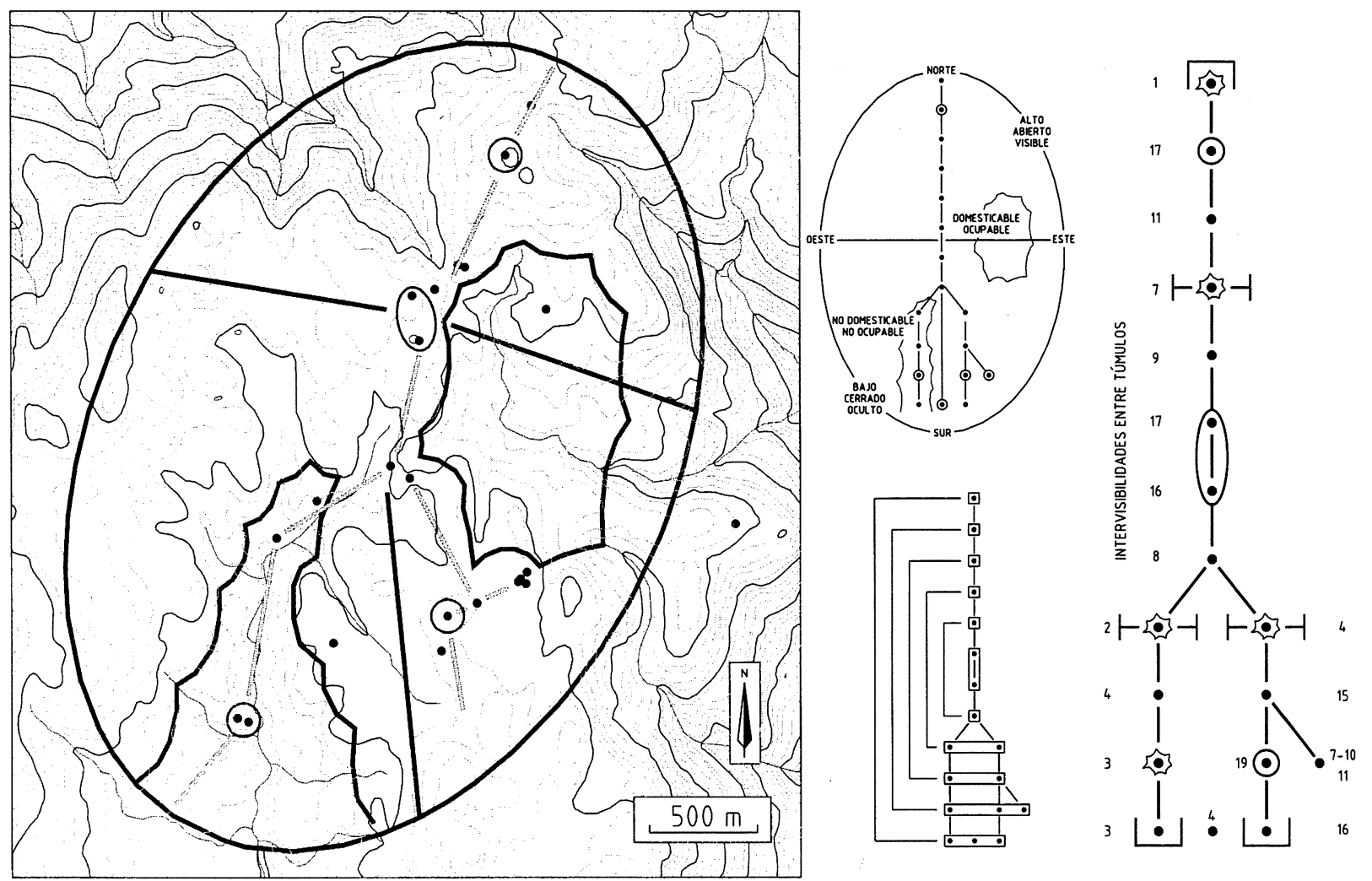

Fig. 9. Representación esquemática de la estructura organizativa del paisaje monumental de la sierra (arriba, en el centro), traslación de la misma al espacio físico (izquierda), y representación de las correspondencias simétricas del sistema tumular (abajo, en el centro, y derecha).

ponde con la cuenca del Barbanza. Este grupo nos ofrece un ejemplo de simetría inversa, pues teniendo el mismo número de tramos que el grupo que discurre paralelo, presenta características opuestas: mientras el segundo ocupa zonas elevadas, el primero se encajona a lo largo de una zona deprimida. Además, aplicando las normas formales que estamos definiendo en el sistema, tendríamos que buscar un túmulo en el tramo del Barbanza que marque su centro y ocupe una posición paralela al monumento 15, que marca el centro del otro lado. Dado que por tratarse de una zona baja no podemos esperar encontrar un túmulo que destaque por su visibilidad, tendríamos que encontrar un monumento singular por algún otro rasgo. Curiosamente, el túmulo que se encuentra en esta posición es el de Arca da Barbanza (11) que representa la construcción megalítica más monumental de toda la SB y una de las de mayor porte de Galicia.

Para completar la definición de este sistema tenemos que recordar que el sistema en su conjunto se introduce dentro de un espacio visual circular y cerrado, cuyo centro representan los túmulos 6 y 7, a partir de los cuales se aíslan sendas mitades Norte y Sur, delimitadas visualmente. Esta circunstancia debe ser muy significativa y producto de una actitud intencional porque en ciertos casos (el túmulo 6 , pero también 2 o 3 ) si se hubiera querido emplazar el túmulo dominando una amplia panorámica visual hacia el exterior de la sierra, se habría conseguido desplazando el monumento unas decenas de metros. Este rasgo se documenta en muchos ejemplos gallegos de emplazamiento de túmulos en sierras, y parece mostrar, además de una cierta indiferencia por controlar esas panorámicas, una voluntad firme por vincular el monumento a escenarios espaciales delimitados visualmente.

Asimismo, las mitades definidas hacia el Este y Oeste de la alineación Norte-Sur de túmulos presentan como rasgo simétrico el estar ocupadas por las dos cuencas definidas previamente: la de $\mathrm{A}$ Graña al Este y la del Barbanza al Oeste. Aquí se acaba la semejanza entre ambas, que se completa 
con una correspondencia inversa bastante clara: mientras la cuenca occidental está ocupada por túmulos, la oriental carece de ellos; ésta en cambio es la zona más adecuada para el asentamiento humano y, como indican los diagramas polínicos, pudo haber estado en uso doméstico en momentos megalíticos, mientras que la primera presenta condiciones geográficas que la hacen inhóspita para un uso u ocupación prolongada.

Podemos ahora hacer una descripción formal del sistema íntegro. Si las observaciones realizadas son ciertas, tendríamos que el conjunto tumular de la SB está organizado en función de un programa completo con normas complejas. El modelo de organización-estructuración del paisaje sería en síntesis el siguiente (Fig. 9):

Un espacio circular delimitado visual y topográficamente, sobre el que la distribución de túmulos introduce un centro principal y marca un eje Norte-Sur que corta ese espacio en dos mitades con características opuestas. La mitad oriental ofrece un entorno en el que predominan las formas elevadas, el relieve abierto y en el que no se presentan obstáculos para la vista (hasta $3 \mathrm{~km}$ ): es por lo tanto un espacio alto, abierto y visible. La mitad occidental en cambio (o más bien el cuadrante Sur de esta mitad) presenta un entorno en el que dominan las formas deprimidas, el relieve cerrado y fragmentado y en el que no es posible establecer relaciones visuales más que a corta distancia ( $1 \mathrm{~km}$ máximo): es por lo tanto un espacio bajo, cerrado y oculto. A su vez, la mitad oriental se completa con una cuenca apta para la ocupación humana y actividades en definitiva domésticas, mientras la occidental es inhóspita y predomina el inculto.

Este modelo general se reproduce en unidades discretas más pequeñas en las que se subdivide el espacio a partir del centro geométrico del sistema. En concreto la primera unidad se corresponde con este centro y a ella se yuxtapone por el Norte otra unidad discreta semejante y por el Sur dos más, una en el cuadrante Sureste y otra en el Suroreste.

\subsection{La temporalidad del paisaje monumental}

Procede ahora hacer unas breves consideraciones sobre la diacronía del sistema. Esto supone tratar tanto el problema de su formación como el de su permanencia y recuperar el grupo de túmulos tipo Pedra da Xesta (23 a 27), que presentan la misma tipología y se individualizan perfectamente de los restantes monumentos de la SB. En principio prescindimos de ellos en el análisis anterior porque su presencia distorsionaba los resultados del proceso. Podemos ahora reintroducirlos y veremos cómo encajan dentro del paisaje monumental.

El grupo de Pedra da Xesta se sitúa en el centro mismo del sistema. Por su parte, los otros cuatro túmulos de este tipo reconocidos en Barbanza (28, 29 y dos fuera del mapa), aunque se encuentran a considerable distancia del sector central de la sierra, se sitúan en cada una de las tres líneas de tránsito que conducen hacia el interior de la misma desde la periferia y que se corresponden con la prolongación de las tres líneas de tránsito que remarca el diagrama de permeabilidad analizado.

Es más, este grupo se emplaza exactamente en el centro o eje natural del espacio de la sierra, en un punto que constituye un pequeño collado, que crea de hechó el vínculo entre dos formas elevadas (Fig. 10). Si con economía de medios, es decir,

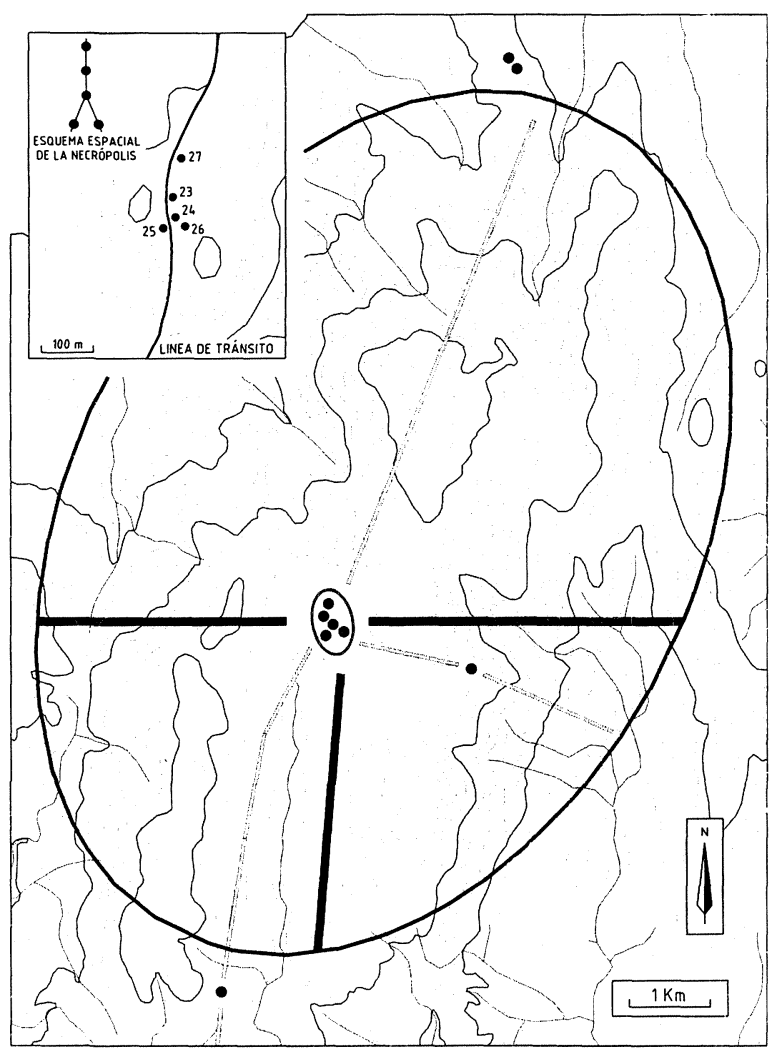

Fig. 10. La primera fase del paisaje monumental: constitución básica de la estructura organizativa posterior y detalle del emplazamiento del grupo de Pedra da Xesta (en el recuadro). 
haciendo un número muy limitado de construcciones, hubiera que remarcar el centro del sistema, éste se pondría más sobre Pedra da Xesta que en el emplazamiento de 6 o 7. Estos dos monumentos sólo pueden operar como centro del sistema porque se complementan con otros monumentos que los equilibran ( 3 y 4 hacia el Norte y 8 y 13 hacia el Sur, todos en posición simétrica y complementaria).

Por otra parte, parece muy indicativo el hecho de que la organización interna del grupo de Pedra da Xesta reproduzca el diseño del esquema formal que estamos considerando y la disposición de las tres líneas de tránsito antes citadas.

$\mathrm{Si}$ a esto le añadimos que la evidencia cronológica parece indicar la prioridad temporal de este tipo de construcciones sobre los restantes tipos del megalitismo galaico, tendríamos aquí el testimonio de que los principios de articulación y organización del espacio tumular se impusieron desde el primer horizonte de construcciones monumentales y de que este modelo se mantuvo en sus líneas generales en momentos posteriores. Éstos, si algo hicieron, fue conferir mayor desarrollo, espesor y concreción a un modelo preexistente.

Esto nos lleva a otro problema: valorar la significación de esta aparente larga duración del sistema. Procede hacer unas consideraciones sobre lo que esta concordancia indica en relación con la temporalidad del ciclo megalítico

La continuidad significa ante todo permanencia del mismo modelo de comprensión del espacio natural, contenido en sus propias formas; significa que el paisaje monumental del megalitismo pleno de la SB incorpora un modelo de organización del espacio construido en el megalitismo inicial con recursos limitados y de escala reducida que a su vez se basa en una profunda comprensión de la lógica natural.

Sin embargo, al tiempo que hay una incorporación de la tradición anterior, hay una cierta ruptura subrayada por el hecho de que las construcciones tipo Pedra da Xesta no se involucran en el modelo final. El examen de las relaciones de intervisibilidad tumular parece indicar que el modelo final hizo cierto uso práctico de los monumentos del primer momento. Prueba de ello sería que: la 'ruta megalítica' que atraviesa Barbanza está denotada por la existencia de relaciones de intervisibilidad entre los túmulos de cada intervalo; esta norma se incumple únicamente entre los túmulos 6-7 y 813; sin embargo la ruptura es falsa pues la relación la reestablece la intrusión del grupo de Pedra da Xesta en el centro de ese intervalo, existiendo intervisibilidad de los monumentos 6 y 7 con los 23 27 y a continuación entre éstos y los 8 y 13 .

La construcción del monumento de Dombate a principios del III milenio a.C., sobre otro monumento más pequeño y primitivo que quedó subsumido en el final (Bello, 1995: 49-50) es ejemplo del fenómeno de incorporación de las obras de fases iniciales por parte del megalitismo pleno. En ambos casos hay una relación de ambigüedad: como todo ejemplo de incorporación de una tradición cultural por otra, es al tiempo un acto de reafirmación de lo anterior y de negación o superación de ello. Se realiza un uso estratégico del pasado para legitimar una nueva situación.

\subsection{El modelo estructural del paisaje monumental (el sentido del espacio)}

Para acabar arriesgaremos algunas interpretaciones sobre el sentido que originalmente habrían transmitido o poseído las tecnologías de construcción del paisaje y de percepción del espacio que hemos intentado descubrir en la SB.

Si intentamos hacer una descripción del modelo estructural (15) que subyace detrás de este modelo de articulación formal del paisaje, es posible que accedamos, desde la materialidad del propio sistema y sin introducir valoraciones o prejuicios extraños, a parte del sentido cultural de este código espacial.

El modelo de articulación que se nos presenta concibe al espacio social como una unidad cerrada (panorámicas delimitadas) de morfología circular, introducida dentro de la naturaleza y en parte diluida en ella (pues el principio de codificación empleado reutiliza los recursos naturales y se basa en una comprensión profunda del espacio natural), y en parte construida sobre ella (pues sustantiva con elementos artificiales ese espacio natural), ocupada por un centro de carácter ceremonial y funerario, con dos mitades muy claras y de signo opuesto: una abierta a la acción humana de carácter doméstico, y la otra cerrada, oculta y orientada hacia el lado inculto e inhóspito de la naturaleza.

En un sentido más interpretativo, pero pegados lo más posible a la materialidad de las correspon-

(15) Utilizamos el término 'descripción' en el sentido definido por Santos et alii, 1997.

T. P., 55, n. $^{\circ} 1,1998$ 
dencias formales, podemos decir que la vinculación monumento/tránsito indica que el túmulo funciona como referente artificial de un complejo código de señales que transmite información sobre las rutas. Además de la función práctica, evidentemente también tenía una dimensión simbólica importante. Por una parte vinculaba el mundo de la muerte con el camino y representaba el vínculo entre la vida y la muerte, basada en una metáfora del movimiento y el discurso. Por otra utilizaba dramática y escenográficamente el movimiento, el acceso y la aproximación al túmulo, como un recurso básico para construir su monumentalidad.

O dicho de otro modo: el proceso de domesticación simbólica del espacio se apoya en un control del espacio-tiempo basado en la visibilidad y permanencia inherente a la construcción monumental y, en el control y manipulación de la experiencia del tiempo y del movimiento sobre el espacio que se produce a través de los túmulos. Al mismo tiempo, la hegemonía de la percepción circular del espacio tal vez se deba entender como una expresión metafórica de la domesticación humana del entorno. La forma circular es la mejor expresión del dominio y el control, del mismo modo que las panorámicas circulares son el fundamento del panóptico.

Encontramos aquí un fenómeno que es de gran importancia en el neolítico europeo: la existencia de patrones circulares de organización del espacio que se concretan en la reutilización de espacios naturales y/o en la construcción de espacios artificiales y, más en general, en la producción de formas de percepción del paisaje basadas en la circularidad. Dejaremos para otro momento el análisis de este tema y con ello la comprobación de que la misma estructura formal que hemos deducido se encuentra en otros niveles espaciales del fenómeno megalítico, como el diseño arquitectónico, y en otros puntos del Neolítico atlántico.

\section{COROLARIO}

La estrategia práctica seguida en este trabajo consistió en contraponer los espacios arqueológicos (ie: la distribución de monumentos, su emplazamiento y las tipologías arquitectónicas; elementos que podemos observar sin necesidad de realizar excavaciones) con los datos geográficos y fisiográficos. Esto nos permitió descubrir las correspondencias y deconstruir los modelos de organización espacial existentes dentro del paisaje ce- remonial megalítico. A partir de aquí pudimos describir el modelo de articulación del paisaje monumental y el posible modelo estructural al que ese paisaje responde. En este análisis nos centramos inicialmente en el estudio de los monumentos más recientes, para volver después sobre los antiguos y adquirir así una visión diacrónica de los cambios y continuidades en el paisaje monumental.

Una consecuencia importante fue descubrir que en diferentes niveles espaciales del paisaje monumental se recuperan los mismos principios de articulación o codificación del espacio. Haciendo una aproximación tipo zoom, comprobamos esta regularidad a nivel de todo el espacio tumular de la SB, de cada una de las unidades o grupos que lo componen y de la organización y disposición concreta de un pequeño grupo de túmulos.

Aunque hemos arriesgado alguna interpretación sobre la significación cultural de estos modelos, creemos que de sus propias características formales se deriva una cierta comprensión débil de los mismos. Intentamos contribuir al programa teórico-metodológico que propusimos en otro punto (Criado, 1993a) para desarrollar dentro de la Arqueología los procedimientos necesarios para evaluar los contenidos implícitos en la materialidad del registro arqueológico, reconociendo éstos por sí mismos y sin necesidad de cargar de interpretación subjetiva nuestra práctica.

Es necesario hacer una crítica radical de la $\mathrm{Ar}$ queología Fenomenológica (Shanks, 1992, Thomas, 1996, Tilley, 1994). No se trata de reconstruir el sentido original a partir de la percepción que nosotros experimentamos en la actualidad. Esto supondría postular la existencia de una subjetividad transcultural cuya proximidad subjetiva a la nuestra nos permitiría comprenderla. Se trata antes bien de percibir desde una subjetividad otra distinta, porque la forma como se manifestaron los fenómenos de la primera poseen una materialidad que se impone a la nuestra.

El precio a pagar por esta tentativa es, además de los riesgos que se asumen, limitar la interpretación a las observaciones con más peso objetivo e inhibir en cambio la pulsión interpretativa de parte de los arqueólogos actuales: stop making sense.

\section{AGRADECIMIENTOS}

A Isabel Cobas y David Barreiro por soportar con nosotros en el campo temperaturas extremas. 
A Tito Concheiro por la información facilitada sobre algunos de los túmulos. A nuestros compañeros de GIArPa por el ambiente de trabajo y estímulo colectivo. Anxo Rodríguez Paz ha delineado, como siempre, las figuras.

\section{BIBLIOGRAFÍA}

Alonso Mathías, F. y Bello Diéguez, J.M. (1997): “Cronología y periodización del fenómeno megalítico en Galicia a la luz de las dataciones por carbono 14". En A. Rodríguez (ed.): O Neolítico Atlántico e as orixes do Megalitismo: Actas do Coloquio Internacional (Santiago de Compostela, 1-6 de abril de 1996): 507520. Universidade de Santiago de Compostela. Santiago.

Amado Reino, J. (1996): "La aplicación del GPS a la Arqueología". Trabajos de Prehistoria, 54 (1): 155-165.

Bello DiéGuez, J.M. (1995): "Arquitectura, arte parietal y manifestaciones escultóricas en el megalitismo noroccidental". En F. Pérez Losada y L. Castro Pérez (coord.): Arqueoloxía e arte na Galicia prehistórica e romana. Monografías del Museo Arqueolóxico e Histórico de A Coruña, 7: 29-98. Coruña.

Criado Boado, F. (1989a): "Megalitos, Espacio, Pensamiento". Trabajos de Prehistoria, 46: 75-98.

- (1989b): "Arqueología del Paisaje y Espacio Megalítico en Galicia". Arqueología Espacial, 13: 61-117.

- (1993a): "Visibilidad e interpretación del registro arqueológico". Trabajos de Prehistoria, 50: 39-56.

- (1993b): "Límites y posibilidades de la Arqueología del Paisaje". Spal, 2: 9-55.

- (1996): "La Arqueología del futuro, ¿el Futuro de la Arqueología?". Trabajos de Prehistoria, 53 (1): 15-36.

- (1997): "La Arqueología del Paisaje como programa de gestión de recursos arqueológicos". En F. Criado (dir.): Memorias del Espacio. La culturización del espacio en la Prehistoria. Monografías de Arqueología del Paisaje, 1. Ediciós do Castro. A Coruña.

Criado Boado, F.; Aira Rodríguez, M.J. y Díaz-Fierros VIQUEIRA, F. (1986): La construcción del paisaje: megalitismo y ecología en la Sierra de Barbanza. Arqueoloxía/Investigación, 2. Santiago.

Criado Boado, F. y Vaquero Lastres, J. (1993): "Monumentos, nudos en el pañuelo. Megalitos, nudos en el espacio". Espacio, Tiempo y Forma, Prehistoria, 6: 205-48.

Filgueiras Rey, A. y Rodríguez Fernández, T. (1994): "Túmulos y petroglifos. La construcción de un espacio funerario. Aproximación a sus implicaciones simbólicas. Estudio en la Galicia Centro-Oriental: Samos y Sarria”. Espacio, Tiempo y Forma, Prehistoria, 7: 211-253.

GonZÁLEZ MÉndeZ, M. (1991): "Yacimientos del III milenio a. C.: entre la problemática del Calcolítico y un pasado huidizo". En F. Criado (dir.): El área BoceloFurelos entre los tiempos paleolíticos y medievales. Arqueoloxía/Investigación, 6: 147-72. Santiago.

Hillier, B. y Hanson, J. (1984): The social logic of space. Cambridge University Press. Cambridge

MÉNDEZ FERNÁNDEZ, F. (1991): "El campaniforme tardío: entre un pasado monumental y una cerámica conspicua". En F. Criado (dir.): Arqueología del Paisaje. El área Bocelo-Furelos entre los tiempos paleolíticos y los medievales. Arqueoloxía/Investigación, 6: 17397. Santiago.

- (1994): "La domesticación del paisaje durante la Edad del Bronce gallego". Trabajos de Prehistoria, 51: 77-94.

Santos Estévez, M., Parcero Oubiña, C. y Criado BoaDO, F. (1997): "De la Arqueología Simbólica del paisaje a la Arqueología de los paisajes sagrados". Trabajos de Prehistoria, 54 (2): 1-20.

Shanks, M. (1992b): Experiencing the Past: on the character of Archaeology. Routledge. London.

Thомаs, J. (1996): Time, Culture and Identity. An interpretive archaeology. Routledge. London.

Tilley, C. (1994): A phenomenology of landscape. Places, paths and monuments. Berg. Oxford.

VAquero Lastres, J. (1989): “¿Dónde diablos se esconden nuestros muertos que no los podemos ver? Reflexiones sobre el emplazamiento de los túmulos del NW". Gallaecia, 11: 81-108.

- (1990): "Ríos y Tumbas. Sobre el emplazamiento de túmulos en el NW peninsular". Trabalhos de Antropologia e Etnologia, 30: 151-75.

- (1992): "Del análisis del emplazamiento al estudio de la distribución de túmulos en el Noroeste". Brigantium, 7: 151-76.

VILlOCH VÁzQuez, V. (1995a): “Análisis del emplazamiento tumular en Galicia: el caso de la necrópolis de Saídos das Rozas (Campo Lameiro-Pontevedra)". EnActas del XXII Congreso Nacional de Arqueología (Vigo, 1993), 1: 373-8. Concello de Vigo - Xunta de Galicia. Vigo.

- (1995b): "Monumentos y petroglifos: la construcción del espacio en las sociedades constructoras de túmulos del noroeste peninsular". Trabajos de Prehistoria, 52 (1): 39-55.

- (1995c): "Contribución al análisis del emplazamiento tumular: La necrópolis de As Travesas (Abegondo-A Coruña)". Minius, IV: 25-37.

Villoch Vázquez, V. y Barreiro Martínez, D. (1997): “¿Arqueología vs. energía eólica?”. Boletín del Instituto Andaluz del Patrimonio Histórico, 20: 103-108.

T. P., 55, n. ${ }^{\circ} 1,1998$ 